\title{
Planning a sustainable metropolitan area: an integrated management proposal for Tijuana-Rosarito-Tecate, Mexico
}

\author{
R. Rojas-Caldelas ${ }^{1}$, R. Venegas-Cardoso ${ }^{1}$, A. Ranfla-Gonzalez ${ }^{2}$ \\ \& C. Pena-Salmon ${ }^{1}$ \\ ${ }^{I}$ Faculty of Architecture, Autonomous University of Baja California, \\ Mexico \\ ${ }^{2}$ Social Sciences Research Institute, \\ Autonomous University of Baja California, Mexico
}

\begin{abstract}
Tijuana, Playas de Rosarito and Tecate form a recent metropolitan area, characterized by high rates of population growth and economic activity, in a short period of time it has become the fifth biggest metropolitan area in Mexico. This fact has influenced federal, state and municipal governments to initiate a series of meetings in order to make a proposal for the planning and management of the area. The proposal includes an integrated assessment about current conditions of social, economic and environmental issues in order to develop some strategies for its management. Then we deal with environmental issues in order to achieve sustainable development concerning water uses, energy, risks, solid wastes, land uses and conservation areas. After the assessment, there were some strategies suggested for resource management within inner city, periurban and suburban fringes. Finally, the paper points out some practical shortcomings related to planning and management: the lack of coordination among public institutions, a weak implementation of municipal regulations, scarce environmental data and the implementation of monitoring. As well as a fragmented planning with remarkable priorities differences that have not matched in time, space and financial resources, at all.
\end{abstract}

Keywords: Urban Environmental Assessment, Sustainable city, metropolitan land use planning, Urban Planning in Mexico. 


\section{Introduction}

Urban planning in Mexico has considerably transformed from 1976 when the Law for Human Settlements was created. At that time urban planning was seen as a matter of an inside exercise oriented to land use regulation, where links to other towns or regions were not relevant for local planning purposes. In a similar situation were social, economic and environmental issues, they were only used for the estimation of demands and programming of public services, utilities, and land reserves for different time scenarios. The planning framework was then developed and implemented from the top federal level to a municipal one. Thus federal and even state planning institutions gave little importance to public opinion (and even less to decision making) and involvement in the making of urban plans and programs and their management.

Nowadays, urban regional planning has changed considerable from the academy and professional practice perspective and not much inside institutional framing on which updating have not yet concluded in some levels such as of law, regulations and institutional organization changes, technology use on the making of plans and programming techniques, communicating information and action monitoring.

Nevertheless, this paper tries to integrate new perspectives of urban and regional planning into practice of the Metropolitan Area Tijuana-Rosarito and Tecate (MATRT). Some of them are: sustainable development principles; Towns as nodal points within network over a city-region; people involvement in the planning and management process; the multiple use of geographic information systems and; design strategies for different development fringes of the metropolitan area.

\section{Methods}

Boundaries of the metropolitan area were defined in two stages; the first, was through an administrative zoning of municipalities and; the second, was a result of social, economic, and environmental data which has produced by means of ecological regionalization [1] and population conglomerates [2] that display a territorial occupation pattern of four fringes: urban, with an important demographic and economic weight of the city of Tijuana over Rosarito and Tecate that has displayed a dynamic of social and economic growth of medium and small developments to consolidate inner city; periurban, featured by disperse housing and industrial developments, with medium population densities and land occupation, land use mixtures of agricultural, grazing and squatters settlements, all of them have grown closely to the new freeway bypass Tijuana-Rosarito; suburban, characterized by low density occupation of land, small towns with low levels of urbanization.

\section{Results}

In a rough way cities of Tijuana, Playas de Rosarito and Tecate and their municipal lands have been considered part of the metropolitan area, however this 
area is also linked to San Diego and Los Angeles metropolitan region due to economic and social exchanges they have been developed over the time. But for the purpose of this paper the analysis is going to be focused over the Mexican metropolitan area.

Tijuana, Rosarito and Tecate have their origin in the middle XVIII century and their foundations are recognized by the end of 1880. Since then these settlements have had interdependence with the United States, so is the case of the construction of the railroad San Diego-Arizona in 1907. The growth and development of Tijuana and Rosarito as tourist and recreational centers derived from US policies that had prohibited alcohol and gambling in the twenties and thirties. By 1940 they had promoted immigration of Mexican agricultural workers throughout "The Bracero Program" and; later on the Mexican government had supported the Border Industrialization and the National Program of the Border that had laid the foundations of the industrial development of this region for the decade of 1960, activity that has continued in 1980 under the name of Maquilador (assembler) Program. In addition to industrial development, Mexican policies were opened to promote international commerce with the entrance of Mexico to GATT and NAFTA [3].
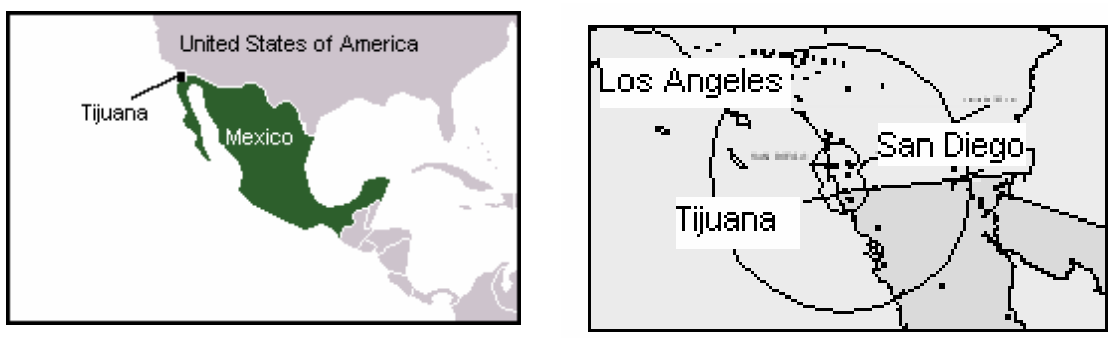

Figure 1: $\quad$ Location of metropolitan Tijuana-Rosarito-Tecate.

In such way from the year of 1980 to the 2000 the population of the three cities and peripheral localities added 466,280 and grew to become 1,306,816 in the 2000. The fast growth is also reflected in the expansion of the urban area that has increased above two times, resulting on rates of annual growth of about $5 \%$, rate above the national average of $2,87 \%$, where Tijuana has a determining weight in regional dynamics. Under this panorama it is clearly seen the need of officially recognizing the existence of a conurbated area between the cities of Tijuana, Rosarito and Tecate [4], that lead on a integration proposal of the three cities like a geographic, economic and social unit for its planning and management.

The conurbation proposal is the origin of the study of territorial management of the MATRT; it includes the planning and management of economic, social, environmental issues. But from all of them this paper is going to deal with the assessment of environmental problems and strategies for the metropolitan area about solid wastes, air quality, green and conservation areas, risks, water, land uses and environmental strategies [5, pp. 122-170]. 


\subsection{Solid wastes}

Among the urgent problems that have the municipalities in the metropolitan area are waste recollection, transfer, treatment and final deposition, as well as to identify and manage clandestine disposition of hazardous, biological infectious and non hazardous wastes in periurban or suburban areas of the cities. One of the main actions taken by governments was the study of characterization of clandestine municipal solid wastes landfills in Tijuana, Tecate and Rosarito. This allowed the identification and selection of sites for the operation of sanitary landfills, the closing of those that did not operate in agreement with the existing regulations and the making of projects under environmental guidelines and standards. The is also a lack of special sites for disposition of tires and non hazardous wastes from industry that has to be considered as public utility in MATRT. Nowadays Tijuana has worked on a new sanitary landfill.

\subsection{Air quality}

The main source of pollution on towns is transport; there is rate of one of three inhabitants that own a vehicle, which means a great production of carbon monoxide $(\mathrm{CO})$, nitrogen oxides $\left(\mathrm{NO}_{2}\right)$ and volatile organic compounds (COV). Another aspect that contributes to pollution is the low use of public transport by people. On second place come suspended particles $\mathrm{PM}_{-10}$ emitted to the atmosphere by the passage of vehicles on nonpaved roads. Third are fixed sources related to industrial activity that goes around $10 \%$ of volatile organic compounds and Rosarito electrical plant with $10 \%$ of $\mathrm{NO}_{2}$. In fourth, emissions from fires, they mean pollution as well as a risk for the population and its goods. Air quality in the metropolitan zone has tend to improve from 1997 to 2005 for all the polluting agents, where in the three first years values above the recommended standards for $\mathrm{PM}_{-10}$ and $\mathrm{NO}_{2}$ were observed. Among the actions that have contributed to this is the change from oil fuel to gas in the Electric Energy plant of Rosarito, the pavement program and renovation of public transport units. Nevertheless, the problem about the old and useless electric energy plant remains, there is a need to accelerate the use of alternative energy sources and to implement hybrid systems by means of incentives, including domestic, commercial and industrial uses, since a high percentage of the energy is generated outside the metropolitan region. The problem of air quality is also affected by the behavior of emissions of fixed and mobile sources in the zone of San Diego and Los Angeles because of airflows patterns in the border region [5, pp. 249-287].

\subsection{Green and conservation areas}

Land use on the metropolitan zone is characterized by native vegetation use, specifically from the chaparral, that covers a surface of $62 \%$. Followed on importance by seasonal and irrigated agriculture and grazing lands, that means $23 \%$ of the surface. The rest of the area belongs to a native vegetation of ecological importance that is distributed along the coast zone (succulent's 
rosettes), water bodies (gallery vegetation) and forests of oak. These lasts shelter flora and fauna species considered rare or in extinction danger. They do not have a defined area, declaration of protection status and a management program according to federal and state environmental protection regulations.

There is an urgent need to modify the perspective of urban green areas used exclusively as public services, without considering their environmental functions and value that might represent linking elements that could structure the cityregion space. On a similar case is the protection of high productive agricultural lands, outstanding beauty landscapes or historical and cultural heritage. Also, there has not been seen the potential of derelict land and abandoned buildings that could be reused. There is also the problem of habitat fragmentation that implies regional utilities networks, mines, landfills, penitentiary facilities, as well as industry of high risk, land uses that demand some regulations to reduce environmental and risk impacts over communities and ecosystems.

\subsection{Risk and vulnerability}

Metropolitan zone is considered go have an average level of seismic danger, although Tijuana and Rosarito have presented values of greater intensity. In addition to seismic danger there are two other kinds of recurrent problems: landslides and flooding both have major negative impacts over squatter settlements within consolidated urban areas. Thus $40 \%$ of the urban population is settled and exposed to some or several types of risk.

Forest fires are seasonal and usually are present when conditions of high temperatures, accumulation of dry biomass and winds exist, affecting grazing, agricultural and native vegetation (chaparral) areas. In 2004 forest fires affected over 6,000 hectares of chaparral, forest and agricultural lands.

Although the probability of tsunamis arrival to Baja California coastal areas is very low, the possibility will always exist. Vulnerable population is located in the coastal corridor of Tijuana-Rosarito, where the major risk is located between Playas de Rosarito and Punta El Descanso. These areas are characterized by active coastal ridges and sometimes very narrow beaches and they do not perform like natural barriers, undergoing an annual erosion of 0.5 to $1 \mathrm{~m}$.

Risks by chemical storage of hazardous substances is higher in the municipality of Tijuana and so because the great number and diversity of substances it handles, meanwhile petrol storage deposits from PEMEX are remarkable in Rosarito.

\subsection{Water}

There is no doubt that water is the main problem of the metropolitan area, regional water resources represent $5.51 \%$ of the total demand, thus the $94.49 \%$ is imported from the Colorado River Basin by the aqueduct of Mexicali-Tijuana as far as $126 \mathrm{~km}$. Regarding underground water, the wells of Rosarito are not longer used because of salinity problems and kept certain restrictions for their use. In the case of wells of the Mission its operation has been controlled and conserved with an annual rate of $51 \mathrm{l} / \mathrm{s}$ and those of the Tijuana-Alamar River 
have a capacity of $430 \mathrm{l} / \mathrm{s}$, although they demand treatment for iron and manganese removal.

Under this panorama it is urgent to establish policies that entail to find other safe long term sources of potable water supply that are enough to cover the demands of the metropolitan area growth, where the most feasible, safe and perhaps most economic option would be the desalination of sea water.

In relation to the installed capacity of sanitary sewage, the metropolitan area shows a $78 \%$ percentage of installed networks, utilities that will have to be expanded in the future to improve its coverage.

\subsection{Land uses}

Land uses for the period of 1993-2005 have showed important changes, urban surface has grown up from 17,523 to 32,188 hectares which represents almost twice the urban expansion of a 12 years period, fact that has affected first of all the areas with no vegetation cover over hills, secondly agricultural and grazing lands and with less importance native vegetation areas, riparian vegetation corridors, oak forests and water bodies in the urban and periurban fringes (Table 1). Given the intense pressure by industrial and real estate developers of continuing its expansion projects towards zones defined as non suitable for urban growth like high productive agricultural lands and natural conservation areas. It is necessary to protect them by low and designate them under a status of protection within the metropolitan land use plan as well as risk areas.

Table 1: $\quad$ Land use changes 1993-2005.

\begin{tabular}{|l|l|l|}
\hline Land uses & $\begin{array}{l}1993 \\
\text { (hectares) }\end{array}$ & $\begin{array}{l}2005 \\
\text { (hectares) }\end{array}$ \\
\hline Seasonal agriculture & 25,724 & 21,164 \\
\hline Irrigated agriculture & 4,219 & 4,037 \\
\hline Grazing lands & 15,737 & 13,502 \\
\hline Riparian vegetation & 2,652 & 2,582 \\
\hline Chaparral & 120,936 & 118,627 \\
\hline No vegetation cover & 4,693 & 729 \\
\hline Native vegetation & 1,757 & 1,704 \\
\hline Water bodies & 606 & 604 \\
\hline Oak forest & 1,290 & \\
\hline Urban area & 17,523 & 32,188 \\
\hline Total & 195,137 & 195,137 \\
\hline
\end{tabular}

Source: Instituto de Investigaciones Sociales, UABC, 2005.

\subsection{Strategies}

Strategies were designed basing on territorial patterns of population distribution and the urban-regional public utilities which allowed integrating social, 
economic and environmental information and its relation with regional networks of communications and administrative zoning.

Therefore three areas of strategic performance were considered that has followed a concentric pattern that goes from urban Tijuana outwards to periurban and suburban fringes. It was because of the economic and demographic importance of Tijuana over other settlements in the region.

a. Urban. It has the best urbanization level compared to Tecate and Rosarito, and also has promoted the rapid growth of the metropolitan area in the last two decades with the highest level of territorial and socioeconomic integration. Recent tendencies of urban growth has shown that small and medium size residential and industrial developments have occupied almost all empty spaces within the limits of the urban fringe. Some of the reasons behind are the introduction of water and sewage systems and the improvement of accessibility by a new highway.

b. Periurbana. This fringe shows a series of small population conglomerates, squatter's settlements and current housing and industrial development projects that shows certain kind concentration toward the Tijuana-Tecate corridor and with less importance toward Rosarito. This pattern could be explained by road structure and accessibility to these communities and Tijuana-Tecate industrial development. The southern part of the fringe has topographical restrictions for developments that have retarded their growth.

c. Suburban. This fringe covers almost a $50 \mathrm{~km}$ radio; small communities with low levels of urbanization, besides agriculture there are just a few and isolated industrial developments like Toyota in Valle de Las Palmas. Most of these settlements are recent ones, from the nineties, and they are also associated with the roads network; nevertheless these communities face constraints of connectivity among fringes due to topographical restrictions. There are growth pressures on agricultural lands by real estate and industrial developers, which would affect lands of high agricultural productivity and ecological values. This fringe has a great number of land uses and mixtures that are not always compatible, so it should be regulated respect to environmental protection and development.

d. Rural. This fringe can be found about $70 \mathrm{~km}$ (average) from the center of Tijuana and is characterized for being mainly rural, where state and federal roads are crucial for the surviving small settlements. The major portion of lands belongs to the municipality of Tecate, dominant land uses are agricultural, forest and conservation of natural areas, in smaller scale there are some low density recreational and tourist centers and second residences of people coming from Mexicali and with less importance from Tijuana and Rosarito that is reason why this area was not considered into the strategies. Finally, it was selected the periurban fringe as an example of proposed environmental strategies. 


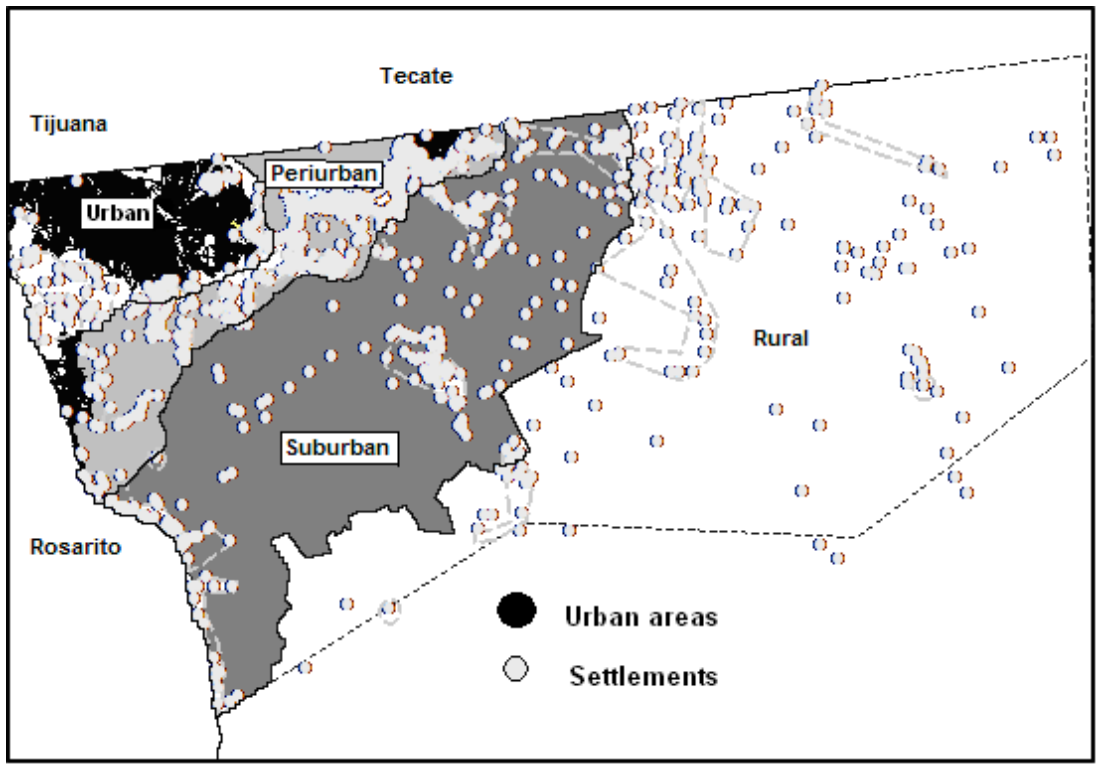

Source: Instituto de Investigaciones Sociales, UABC, 2005.

Figure 2: Zoning of the metropolitan region.

\subsection{Periurban environmental strategies}

Water and sewage systems:

- $\quad$ assessment of seawater desalination plants as an alternative to widen the threshold of water provision demands for medium and long term;

- coordination between developers and water management authorities for the planning and management of water provision and its treatment in medium and large housing and industrial developments;

- $\quad$ assessment of water demands for environmental services.

Energy and transport:

- $\quad$ environmental assessment of gasification plants and conduction lines;

- $\quad$ assessment and implementation of hybrid energy systems for residential and industrial projects;

- $\quad$ introduction of public transport services for commuters (improvement of accessibility between fringes could be achieved by the expansion of primary road structure to peripheral settlements);

- create subsidies to locate environmental certified industries and to enhance pollution prevention practices.

Land uses:

- $\quad$ promotion throughout economic incentives the occupation of planned land use reserves and conditioning developments to absorb costs of introduction of pubic utilities and public services;

- $\quad$ improve urbanization levels in small and medium size settlements; 
- $\quad$ applied environmental regulation to sand and gravel extraction sites, and to introduce strategic environmental assessment for development plan or programmes.

Municipal wastes:

- $\quad$ location and regulation of transference station centre for waste disposal;

- $\quad$ rehabilitation and reuse of closed waste disposal sites;

- $\quad$ reduction and control of open disposal of wastes over roads, brown fields and water courses.

Conservation areas:

- $\quad$ inventory and management of recreation programmes for conservation purposes of water bodies, river basins, canyons, high productive agricultural lands, outstanding beauty landscapes and historic an cultural heritage.

Risk:

- $\quad$ risk prevention and management programmes for natural fires of the chaparral;

- $\quad$ land use restrictions for development over landslides areas, flooding areas, active faults, special and hazardous wastes disposal sites, gas conduction pipelines and other kind of regional utilities projects and to pay attention over non compatible land uses.

\section{Conclusions}

Growth tendency of the metropolitan area has favored industrial location towards the Tijuana-Tecate corridor; meanwhile the Tijuana-Rosarito corridor has done so to residential real estate developments for tourist and recreational purposes. Whereas the space between Rosarito and Tecate has to satisfy the demands of the people from the metropolitan area related to housing and public services.

It is important for the making of the metropolitan land use plan to keep in mind that every fringe has its own problems and solutions, but what they have in common are social, economic and environmental goals in order to have better living standards in the long term.

Tijuana's challenge is water and energy supply in the short and medium term, besides the renovation of the public utilities network system, the regulation of the growth areas with risk restrictions for development and the planning and management of different type of wastes.

In another priority level, there is the making of the program or plan that suitably protects and handles the natural and productive areas in the periurban and suburban fringes, not protecting them would affect many species of threatened flora and fauna or in danger of extinction as well as ecosystems, outstanding beauty landscapes attributes and historical and cultural heritage. In similar situation are agricultural and grazing lands on valleys.

Metropolitan planning and management is complex matter that concerns to different institutions and levels of government, each one of them with different departments organized on sectors by themes (ecology, water, energy, transport 
among others) where planning is independent and has to deal with their own objectives, goals, resources and priorities and it is not, necessarily coordinated with other institutions. So the challenge is to share and build up a common plan to handle multiple problems, joint efforts to be more effective and to define competence levels between local planning and regional planning issues. It is important to design the mechanisms to implement the monitoring of development actions, for that it is deemed necessary to have suitable environmental information on adequate scales to be shared by different users.

\section{References}

[1] SIDUE. "Program of Urban Development and Territorial Ordinance", Baja California State Government, 2004.

[2] UABC-SIDUE, "Urban Management of the Metropolitan Zone of Tijuana-Tecate-Rosarito, Technical Report", Autonomous University of Baja California - Institute of Social Research and Secretary of Infrastructure and Urban Development, Mexicali, Baja California, Mexico, pp. 249-287, 2005.

[3] Páez-Frías, Elías. Processes in the Structuring of the Metropolitan Space: "Towards the definition of a planning model and management for the metropolitan zone Tijuana-Rosarito-Tecate, B.C.”, Master Thesis, Faculty of Architecture, UABC, pp 64-95, Jun 2005.

[4] Baja California State Congress. "Decree of Conurbated Zone of TijuanaTecate-Playas de Rosarito", Oficial Newspaper12 de marzo de 2004.

[5] UABC-SIDUE, "Urban Management of the Metropolitan Zone of Tijuana-Tecate-Rosarito, Technical Report, Autonomous University of Baja California - Institute of Social Research and Infrastructure and Urban Development Secretary, Mexicali, Baja California, Mexico, 2005. 